Ernest W. Johnson, MD

\title{
Back to Water (Or Hydrotherapy)
}

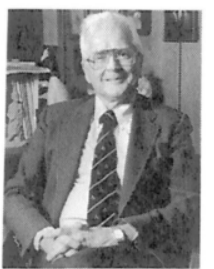

A brief history:

The springs of Ala Sheher in Israel have been used since the 3rd century B.C. Mud and water from the Nile played an important role in purification and healing rites. Cicero's physician, Asclepiades, prescribed a combination of hydrotherapy, light, and massage.

Hippocrates used water therapy with friction to treat muscle and joint disease.

Galen prescribed baths for fever and gave water first place in treatment of disease.

Herod the Great used thermal baths.

Homer preferred to use warm baths for fatigue, injuries, and depression.

1000 B.c. Japanese steam bathers raised the body temperature to 104 degrees $\mathrm{F}$ and followed the heat with cold applications.

Therapeutic pools were prominent in Roman civilization.

Around A.D. 1700 a German physician, Hahn, recommended prolonged immersion in water for leg sores.

John Wesley, founder of the Methodist Church, published a book on water therapy (as a preliminary to baptism by immersion). Just kidding! Only Baptists immerse; Methodists use a few drops on the head.

The 19th century made popular the use of water in medicine, for example, the sauna, douche, wet packs, compresses, and spa therapy. Many of these were recommended for psychiatric conditions. A cold pack followed by a scotch douche can do wonders for a depressed patient.

My reason for raising the issue is my recurring concern with our residents who forget the importance of the therapeutic pool to rehabilitation. Even a quarterly reminder is insufficient to keep this critical subject at the top of the residents' memory cortex. Witness this sample list (not exhaustive) of rehab activities in the pool:

1. The first experience of a severely disabled person (e.g., spinal cord injury [SCI]) in learning how to handle their bodies.

2. To support patients with postural hypotension, for example, diabetic autonomic peripheral neu- ropathy or SCI, whose abdominal muscle can't restore the diaphragm to the full expiratory position when upright.

3. Graded weight-bearing in $41 / 2$ to 3 feet of water.

4. Afferent fiber stimulation for hemiplegic patients who have central sensory compromise (proprioceptive augmentation, to convert it to therapeutic jargon).

5. Inertia of water on incoordination or movement disorders from central nervous system (CNS) dysfunction.

6. General conditioning for "chronic pain" patients. Also can reduce pain.

7. Early non-weight-bearing movements for patients with acute low back pain and other acute musculoskeletal injuries.

Not inappropriately it also can (and should) be used for teaching swimming skills to disabled persons.

Other water uses include contrast baths for limb pain, and whirlpool or Hubbard Tank for debriding. In addition, the Hubbard Tank with Dreft soap qod makes a masterful improvement on the bed bath for the severely disabled patient.

This modality isn't new but it's often forgotten.

Water as a therapeutic modality is remarkably versatile. It has a high specific heat which makes it an effective conductive and convective heating agent.

Archimedes' Principle states that a body immersed in water will be supported (buoyed up) by a weight equal to the weight of the volume of the water displaced. The specific weight of water is one (1), as is the human body. How superbly water is conditioned for physical rehabilitative activities.

\section{USE IT OFTEN!}

N.B. Therapeutic pools need temperatures of 93-94 degrees F. Recreational pools are appropriately kept between 78 and 82 degrees $\mathrm{F}$.

Whirlpool water temperatures are usually maintained at 110 degrees $\mathrm{F}$, but compressed air is added so the result is a safe 104 degrees $\mathrm{F}$.

At your next program planning session (read-order writing)

\section{THINK WATER!}

